Zwikker, H.E., Ende, C.H. van den, Lankveld, W.G. van, Broeder, A.A. den, Hoogen, F.H. van den, Mosselaar, B. van de, Dulmen, S. van, Bemt, B.J. van den. Effectiveness of a group-based intervention to change medication beliefs and improve medication adherence in patients with rheumatoid arthritis: a randomized controlled trial. Patient Education and Counseling: 2014, 94(3), 356-361

\begin{tabular}{|l|l|}
\hline $\begin{array}{l}\text { Postprint } \\
\text { Version }\end{array}$ & 1.0 \\
\hline Journal website & http://www.pec-journal.com/article/S0738-3991(13)00516-8/abstract \\
\hline Pubmed link & $\underline{\text { http://www.ncbi.nlm.nih.gov/pubmed/24388126 }}$ \\
\hline DOI & $10.1016 /$ j.pec.2013.12.002 \\
\hline
\end{tabular}

This is a NIVEL certified Post Print, more info at http://www.nivel.eu

\title{
Effectiveness of a group-based intervention to change medication beliefs and improve medication adherence in patients with rheumatoid arthritis: A randomized controlled trial
}

HANNEKE E. ZWIKKER ${ }^{A}$, CORNELIA H. VAN DEN ENDE ${ }^{A}$, WIM G. VAN LANKVELD ${ }^{\mathrm{B}}$, ALFONS A. DEN ROEDER ${ }^{A}$, FRANK H. VAN DEN HOOGEN ${ }^{A}$, BIRGIT VAN DE MOSSELAAR ${ }^{A}$, SANDRA VAN DULMEN $^{\mathrm{C}, \mathrm{D}, \mathrm{E}}$, BART J. VAN DEN BEMT ${ }^{\mathrm{A}, \mathrm{F}}$,

\begin{abstract}
Objective: To assess the effect of a group-based intervention on the balance between necessity beliefs and concern beliefs about medication and on medication non-adherence in patients with rheumatoid arthritis (RA).

Methods: Non-adherent RA patients using disease-modifying anti-rheumatic drugs (DMARDs) were randomized to an intervention or control arm. The intervention consisted, amongst others, of two motivational interviewing-guided group sessions led by the same pharmacist. Control patients received brochures about their DMARDs. Questionnaires were completed up to 12 months followup.

Results: 123 patients (mean age: 60 years, female: 69\%) were randomized. No differences in necessity beliefs and concern beliefs about medication and in medication non-adherence were detected between the intervention and control arm, except at 12 months' follow-up: participants in the intervention arm had less strong necessity beliefs about medication than participants in the control arm (b: -1.0 (95\% CI: -2.0, -0.1)).

Conclusion: This trial did not demonstrate superiority of our intervention over the control arm in changing beliefs about medication or in improving medication adherence over time.

Practice implications: Absent intervention effects might have been due to, amongst others, selection bias and a suboptimal treatment integrity level. Hence, targeting beliefs about medication in clinical practice should not yet be ruled out.
\end{abstract}


Zwikker, H.E., Ende, C.H. van den, Lankveld, W.G. van, Broeder, A.A. den, Hoogen, F.H. van den, Mosselaar, B. van de, Dulmen, S. van, Bemt, B.J. van den. Effectiveness of a group-based intervention to change medication beliefs and improve medication adherence in patients with rheumatoid arthritis: a randomized controlled trial. Patient Education and Counseling: 2014, 94(3), 356-361

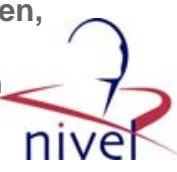

\section{INTRODUCTION}

Adherence to disease-modifying anti-rheumatic drugs (DMARDs) in patients with rheumatoid arthritis (RA) is not optimal and ranges from $22 \%$ to $107 \%{ }^{[1], \text { [2], [3], [4] and }}$

${ }^{[5]}$. As non-adherence can reduce treatment efficacy and can intensify disease activity, pain, joint damage and a lower quality of life ${ }^{[6],[7] \text { and [8] }}$, interventions to improve adherence are warranted.

Existing interventions to improve medication adherence in chronic diseases are mostly complex and of limited effect ${ }^{[9]}$. To date, three studies have assessed the effectiveness of a medication adherence intervention in RA ${ }^{[10],[11] \text { and [12] }}$. Only one of these studies demonstrated a slight improvement in adherence to D-penicillamine following a patient education program ${ }^{[11]}$, but this program was intensive (51 individuals $\times$ six sessions $\times 30 \mathrm{~min}$ ).

Time-efficient and effective adherence interventions are, thus, needed. Therefore, we developed a short, group-based intervention to improve medication adherence in non-adherent patients with RA using DMARDs ${ }^{[13]}$. Of the five WHO domains comprising possible targets for adherence improving interventions (i.e., the socioeconomic, healthcare system, condition-related, therapy-related and the patientrelated domain) ${ }^{[14]}$, our intervention focusses on the patient-related domain. It aims to improve adherence by resolving patients' practical barriers to taking medication, and by improving patients' individual balance between necessity beliefs and concern beliefs about medication. Despite the apparent association between these beliefs and

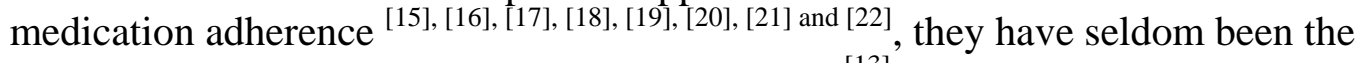
main focus of adherence-improving interventions ${ }^{[13]}$.

This randomized clinical trial evaluated the effectiveness of our group-based intervention on medication beliefs (primary outcome of interest) and adherence in non-adherent patients with RA.

\section{METHODS}

\subsection{Design}

This is a single-center, researcher-blinded randomized clinical trial. Participants were randomly allocated to two arms at a ratio of 1:1, and were asked to complete questionnaires at baseline (T0), and at one week (T1), six months (T2), and one year (T3) after the second group session (Section 2.3). In addition to questionnaires, refill data were used to assess medication adherence. This trial was approved by the local medical ethical board (CMO 2009/090; NCT00968266), and has been reported according to the CONSORT guidelines ${ }^{[23]}$.

\subsection{Participants and recruitment}

Patient inclusion took place between September 2009 and February 2011 at the Sint Maartenskliniek (SMK Nijmegen, the Netherlands), a clinic specialized in rheumatology, rehabilitation and orthopedics.

Consecutive, adult patients having RA for at least one year according to the 2010 ACR-criteria ${ }^{[24]}$ and using at least one DMARD were screened for eligibility by their rheumatologist during regular outpatient visits. Patients with severe mental or physical constraints or illiterate in the Dutch language were excluded. Eligible patients filled in an informed consent form and questionnaires (including the 
Zwikker, H.E., Ende, C.H. van den, Lankveld, W.G. van, Broeder, A.A. den, Hoogen, F.H. van den, Mosselaar, B. van de, Dulmen, S. van, Bemt, B.J. van den. Effectiveness of a group-based intervention to change medication beliefs and improve medication adherence in patients with rheumatoid arthritis: a randomized controlled trial. Patient Education and Counseling: 2014, 94(3), 356-361

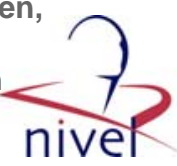

Compliance Questionnaire Rheumatology for adherence assessment (CQR)) ${ }^{[25]}$ at home. Subsequently, as we only wanted to include non-adherent patients, patients taking $\leq 80 \%$ of prescribed medication according to the CQR were telephonically invited for trial participation. Interested patients were scheduled for an intake meeting with one of the two involved researchers [BvdM/HZ]: trial information was discussed and written informed consent was obtained.

\subsection{Interventions}

\subsubsection{Intervention arm (arm 1: sessions)}

The systematic development of the intervention (based on the Intervention Mapping framework) ${ }^{[26]}$ and its content is published by Zwikker et al. in this journal ${ }^{[13]}$. The intervention consisted of two motivational interviewing (MI) guided ${ }^{\text {[27] }}$ group sessions (one week apart, with 5-7 RA patients), designed to improve patients' balance between necessity beliefs and concern beliefs about medication and to resolve patients' practical barriers to medication taking. During the Intervention Mapping process, beliefs about medication and practical barriers were selected as intervention targets by an interdisciplinary expert group, based on a (1) literature study, (2) cross-sectional study, and (3) focus groups. MI was chosen as central communication style, amongst others, for its suitability to explore patients' individual ambivalence regarding necessity - and concern beliefs about medication.

Two pharmacists alternately led the pair of sessions. During these sessions, the participants made an inventory of their own medication beliefs and practical barriers to take medication. These were non-judgmentally discussed in the group, with coparticipation of a rheumatologist during the second session. Participants were encouraged to provide constructive feedback and solutions. The session closed with handing out brochures about the DMARDs that the patients were using.

Four of nine pairs of sessions were randomly audio-recorded and analyzed: an independent assessor checked treatment integrity in terms of potential omission errors in the intervention content ${ }^{[28]}$ and the degree of patient-centeredness (or MI * ambiance' as measured with the validated BECCI-instrument ${ }^{[29]}$, see Appendix I).

\subsubsection{Control arm (arm 2: brochures)}

Participants allocated to the control arm received brochures at home about the DMARDs they were using at the time, with a request to thoroughly read the brochures.

\subsection{Trial randomization and implementation}

Appendix Figure I presents the randomization and implementation process. (See online Supplementary Material).

A blinded, computer-generated randomization list was obtained [BvdB] for subjects in permuted blocks of $10^{[30]}$. Based on order of inclusion and availability, patients were allocated to one of nine clusters between 2009 and 2011 (one cluster consisted of 12-14 patients, half of whom were allocated to arm 1 and the other half to arm 2). 
Zwikker, H.E., Ende, C.H. van den, Lankveld, W.G. van, Broeder, A.A. den, Hoogen, F.H. van den, Mosselaar, B. van de, Dulmen, S. van, Bemt, B.J. van den. Effectiveness of a group-based intervention to change medication beliefs and improve medication adherence in patients with rheumatoid arthritis: a randomized controlled trial. Patient Education and Counseling: 2014, 94(3), 356-361

The researcher was responsible for data collection and - analyses, and remained blind to treatment allocation.

\subsection{Measures}

\subsubsection{Baseline characteristics (T0)}

Socio-demographic factors measured were age, sex, living with others, educational level, and employment status. Clinical factors measured were disease duration and physical functioning (such as physical abilities and pain severity, see Appendix Table I).

Electronic hospital/pharmacy data were used to assess the types of DMARDs used at baseline, and to assess the presence of anti-CCP and rheumatoid factor values in the participants (descriptive use only).

\subsubsection{Primary measures (T0, T1, T2, T3)}

Beliefs about medication were measured using the validated Beliefs about Medicines Questionnaire ${ }^{[19]}$, which consists of two parts. Part one, the BMQ 'specific', has two subscales of five items each, measuring patients' beliefs about the necessity of prescribed medication (e.g., "Without my medicines I would be very ill”), and their concerns about potential adverse consequences of taking the medication. Within the subscales, items are scored from 5 (strongly agree) to 1 (strongly disagree) and are summed to obtain a total score ranging from 5 to 25 . Higher scores indicate stronger beliefs. By subtracting the concerns score from the necessity score, a necessityconcerns differential score can be calculated (ranging from -20 to +20 , where positive scores mean that patients perceive that benefits of medication outweigh costs, and vice versa).

Part two, the BMQ 'general', assesses general beliefs about pharmaceuticals as a class of treatment ${ }^{[20]}$, and also has two subscales of four items each. The 'overuse' subscale includes beliefs about the way in which medicines are endorsed by doctors (e.g., "Doctors place too much trust on medicines"). The 'harm' subscale includes beliefs about the potential of medication to harm (e.g., "Medicines do more harm than good"). The scoring method is identical to the BMQ 'specific': total subscale scores range from 4 to 20 .

\subsubsection{Secondary measures (T0, T1, T2, T3)}

Medication non-adherence was assessed with the Compliance Questionnaire Rheumatology ${ }^{[25]}$. The CQR is able to detect whether a patient takes $\leq 80 \%$ of prescribed medication (binary score) with a sensitivity of $62 \%$ and a specificity of 95\%.

Non-adherence was also measured using a dichotomized score of the five-item Medication Adherence Report Scale (MARS ${ }^{[31]}$, non-adherent when total score $\leq 23$ 
Zwikker, H.E., Ende, C.H. van den, Lankveld, W.G. van, Broeder, A.A. den, Hoogen, F.H. van den, Mosselaar, B. van de, Dulmen, S. van, Bemt, B.J. van den. Effectiveness of a group-based intervention to change medication beliefs and improve medication adherence in patients with rheumatoid arthritis: a randomized controlled trial. Patient Education and Counseling: 2014, 94(3), 356-361

${ }^{[22]}$ and [41]) and using pharmacy refill data ${ }^{[42]}$. Using these data, Medication Possession Ratios (MPR: days of DMARD supply divided by the number of days within an observation period) were calculated ${ }^{[32]}$. (Calculation) details about the non-adherence measures and other secondary measures that might be affected by our intervention ${ }^{[17]}$ are provided in Appendix Table I ${ }^{\text {[33], [34], [35], [36], [37], [38], [39] and [40]. }}$ All questionnaires used were validated and had a sufficient level of internal consistency in this RA sample (alpha: 0.68-0.95). Reminders were sent to stimulate patients to fill in the questionnaires.

\subsection{Sample size and data analyses}

To detect a difference in the BMQ differential score of two points at 12 months' follow-up between the two arms ${ }^{[15]}$, we aimed to include 60 participants in each arm (based on an alpha of 0.05 , beta of 0.2 , a pilot-derived SD of 3.9, and taking $28 \%$ drop-outs into account).

Data analyses were based on the intention-to-treat principle ${ }^{[23]}$, and on complete cases. For all outcomes except refill rates (MPRs), intervention effects were analyzed using generalized estimating equations (GEE ${ }^{[43]}$ ) with robust standard errors ${ }^{[44]}$, two-sided p set at 0.05 , and an assumed unstructured correlation working matrix. Beforehand, severely skewed outcomes were dichotomized (MARS and SIMS, cutoff at $95 \%$ of their scales ${ }^{[22] \text { and }[41]}$ ). Furthermore, one fixed set of confounders was selected from the baseline measures (selected when visually unbalanced between the arms ${ }^{[45]}$, univariately associated with $\geq$ one outcome measure, and when not strongly correlated to other potential confounders). Time was handled as a dummy variable [46].

Intervention effects as assessed by refill data, and differences between the nonadherent trial participants and the non-adherent patients who refused to participate were tested by means of $t$-tests (unequal variances assumed) or Chi-square tests. Baseline scores of the initial sample and the remained sample at 12 months' followup were compared using standardized mean differences to assess the influence of attrition on the study results ${ }^{[47]}$. All data analyses were verified by a statistician.

\section{RESULTS}

\subsection{Participants and attrition}

1819 RA patients were assessed for eligibility; the participant flow trough the trial is depicted in Fig. 1. The 123 non-adherent, randomized patients did not differ in terms of baseline characteristics and outcome measures from the 118 non-randomized, nonadherent patients.

\section{[FIGURE 1]}

Overall attrition in the baseline sample up to 12 months after baseline was $8.9 \%$, and had no influence on the main outcomes of this study. 
Zwikker, H.E., Ende, C.H. van den, Lankveld, W.G. van, Broeder, A.A. den, Hoogen, F.H. van den, Mosselaar, B. van de, Dulmen, S. van, Bemt, B.J. van den. Effectiveness of a group-based intervention to change medication beliefs and improve medication adherence in patients with rheumatoid arthritis: a randomized controlled trial. Patient Education and Counseling: 2014, 94(3), 356-361

\subsection{Baseline sample characteristics}

Most participants were female and lived together with others. A quarter of the total sample was highly educated. Also, participants had a mean disease duration of $>14$ years (Table 1).

\section{[TABLE 1]}

Descriptive data on all outcome measures at baseline and follow-up are presented in appendix Table II.

\subsection{Effects of the intervention}

Table 2 presents outcomes regarding beliefs about medication and non-adherence at baseline and 12 months' follow-up, and the corresponding adjusted effect sizes.

\section{[TABLE 2]}

Generally, no differences in BMQ scores were detected between both arms over time. Only at 12 months' follow-up, participants in the intervention arm did have less strong necessity beliefs about medication than participants in the control arm. No differences between the two arms could be detected for other secondary outcome measures, except pain and accepting illness cognitions: at one week follow-up, participants in the intervention arm reported less pain (adjusted $b:-7.8,95 \% \mathrm{CI}-$ 13.7, -1.8), and stronger accepting illness cognitions (unadjusted $b$ : 0.9, 95\% CI 0.1, 1.8 , adjusted b not significant) than those in the control arm.

\subsection{Additional analyses}

Three additional analyses were performed.

First, we studied changes in outcomes between the intake meeting and baseline, since we noted that non-adherence had changed between these moments (decreased from $100 \%$ of patients being non-adherent, to $65 \%$ ). It appeared that the balance between necessity - and concern beliefs about medication had improved (paired $t$-test, difference $0.9,95 \% \mathrm{CI}-0.0,1.8)$. Also, the amount of change in CQR adherence in the participants depended on the researchers involved in the inclusion procedure ( $44 \%$ of patients included by researcher ' $A$ ' became adherent at baseline, versus $25 \%$ of patients included by researcher ' $\mathrm{B}$ '; $p=0.03$ ). This association was also reflected in the refill rates: the mean refill rate was $98 \%$ at baseline, and $104 \%$ at 12 months' follow-up in those patients included by researcher 'A', versus $100 \%$ and $93 \%$ by researcher 'B', respectively ( $p<0.05$, paired two sample $t$-test).

Second, in a sensitivity analysis, we found that the direction of our results did not change when excluding patients who were medication-adherent at baseline. Third, treatment integrity analyses were performed (Appendix I). 49\% of the intervention content, as described in the intervention protocol ${ }^{[13]}$ was conducted. In practice, participants had a greater need for education about medication than for discussions about medication use; the intervention leaders felt it was important to 
Zwikker, H.E., Ende, C.H. van den, Lankveld, W.G. van, Broeder, A.A. den, Hoogen, F.H. van den, Mosselaar, B. van de, Dulmen, S. van, Bemt, B.J. van den. Effectiveness of a group-based intervention to change medication beliefs and improve medication adherence in patients with rheumatoid arthritis: a randomized controlled trial. Patient Education and Counseling: 2014, 94(3), 356-361

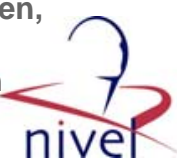

serve this need. The degree of patient-centeredness during the intervention was 3.1 on a scale of 0 ('not at all') to 4 ('a great extent').

\section{DISCUSSION AND CONCLUSION}

\subsection{Discussion}

This study evaluated the effects of a short, group-based intervention, which primarily aimed to change the balance in beliefs about medication, and subsequently, to improve medication adherence to DMARDs in non-adherent patients with RA. However, the intervention was not superior to the control arm in changing beliefs or improving adherence.

Our results are in line with the systematic review by Haynes and colleagues ${ }^{[9]}$, which states that most existing interventions to improve medication adherence are not particularly effective. However, our results do not correspond with the studies by Clifford and Bender ${ }^{[15]}$ and ${ }^{[48]}$, who found that their telephone interventions elicited more positive beliefs about medication and better adherence than the control condition. Since baseline measures were missing ${ }^{[15]}$ or no long term effects had been examined ${ }^{[48]}$ in these studies, however, our results seem to be more solid. To place our results in context, more studies about the effectiveness of targeting beliefs about are needed, though.

There are several explanations for the absence of intervention effects.

First, there may not have been sufficient room for improvement in beliefs and adherence: beliefs and adherence had already favorably changed before the actual intervention took place. This might have been due to the phenomenon of 'regression to the mean' ${ }^{[49]}$, Hawthorne effects ${ }^{[50]}$, but also to our intake meeting ${ }^{[51]}$, a notion supported by the correlation between the change in adherence and the two researchers involved during intake.

Second, although we established a good level of patient-centeredness, the total treatment integrity level of our intervention was suboptimal. This might have affected our study results. In contrast, it is still unknown to what extent a suboptimal treatment integrity level affects treatment outcomes ${ }^{[28]}$, so more research into the topic of treatment integrity is needed.

Third, this trial suffered from selection bias by including patients with a long disease duration (mean: >14 years). Modifying existing beliefs and adherence behaviors in patients with such a long disease duration might be harder to establish than forming new beliefs and behavior in recently diagnosed RA patients who are, essentially, busy with adopting a new lifestyle ${ }^{\lceil 52]}$.

Last, ineffectiveness of our intervention might be due to focusing on patient-related factors only, while non-adherence is also caused by other types of factors according to the WHO ${ }^{[14]}$. Targeting beliefs about medication in RA patients, however, still remains an understandable choice according to a recent systematic review of Pasma et al. ${ }^{[53]}$, indicating beliefs about medication to be one of the most relevant and modifiable determinants of non-adherence in RA patients.

This study has both limitations and strengths regarding internal validity. Nonadherence rates differ according to the questionnaires and the refill rates, for example (60\% versus $1.5 \%$ non-adherence). The refill rate, however, is a medication 
Zwikker, H.E., Ende, C.H. van den, Lankveld, W.G. van, Broeder, A.A. den, Hoogen, F.H. van den, Mosselaar, B. van de, Dulmen, S. van, Bemt, B.J. van den. Effectiveness of a group-based intervention to change medication beliefs and improve medication adherence in patients with rheumatoid arthritis: a randomized controlled trial. Patient Education and Counseling: 2014, 94(3), 356-361

possession measure, rather than a medication adherence measure ${ }^{[54]}$. Moreover, a strong feature of this trial is the combination of three different adherence measures ${ }^{[55]}$. Neither the self-report questionnaires nor the refill rate data showed superiority of the intervention arm over the control arm in changing beliefs or adherence, indicating robustness of findings.

This study has also strengths and limitations regarding external validity. A limitation is that we do not know if our non-adherent trial participants represent non-adherent RA patients in general, since no comparison material is available. A strength was the low attrition rate in our trial ${ }^{[56]}$.

\subsection{Conclusion}

This trial did not demonstrate superiority of our intervention over the control arm in changing beliefs about medication, in improving medication adherence or in improving any other secondary outcome measures over time.

\subsection{Practice implications}

Beliefs about medication are relevant and modifiable determinants of non-adherence in RA patients. Hence, the potential value of targeting beliefs about medication and practical barriers to take medication in improving medication adherence should not yet be ruled out in clinical practice. Ineffectiveness of our intervention, namely, might have been due to selection bias, Hawthorne effects, and a suboptimal level of treatment integrity. Further research on other types of interventions which are embedded in clinical practice (non-trial setting) and with early RA-patients is warranted.

I confirm all patient/personal identifiers have been removed or disguised so the patient/person(s) described are not identifiable and cannot be identified through the details of the story.

\section{CONFLICT OF INTEREST}

None.

\section{FUNDING}

None.

\section{ACKNOWLEDGEMENTS}

We would like to thank all patients for participating in this trial. We would also like to thank Victor Huiskes for leading some of the group sessions.

\section{REFERENCES}

[1] M.A. Blum, D. Koo, J.A. Doshi Measurement and rates of persistence with and adherence to biologics for rheumatoid arthritis: a systematic review Clin Ther, 33 (2011), pp. 901-913

[2] H. Brus, M. van de Laar, E. Taal, J. Rasker, O. Wiegman Determinants of compliance with medication in patients with rheumatoid arthritis: the importance of self-efficacy expectations Patient Educ Couns, 36 (1999), pp. 57-64

[3] D.V. Doyle, D. Perrett, O.J. Foster, M. Ensor, D.L. Scott The long-term use of dpenicillamine for treating rheumatoid arthritis: is continuous therapy necessary $\mathrm{Br} \mathrm{J}$ Rheumatol, 32 (1993), pp. 614-617 
Zwikker, H.E., Ende, C.H. van den, Lankveld, W.G. van, Broeder, A.A. den, Hoogen, F.H. van den, Mosselaar, B. van de, Dulmen, S. van, Bemt, B.J. van den. Effectiveness of a group-based intervention to change medication beliefs and improve medication adherence in patients with rheumatoid arthritis: a randomized controlled trial. Patient Education and Counseling: 2014, 94(3), 356-361

[4] T. Koncz, M. Pentek, V. Brodszky, K. Ersek, E. Orlewska, L. Gulacsi Adherence to biologic DMARD therapies in rheumatoid arthritis Expert Opin Biol Ther, 10 (2010), pp. 1367-1378

[5] T. Pullar, S. Peaker, M.F. Martin, H.A. Bird, M.P. Feely The use of a pharmacological indicator to investigate compliance in patients with a poor response to antirheumatic therapy Br J Rheumatol, 27 (1988), pp. 381-384

[6] I. Contreras-Yanez, L.S. Ponce De, J. Cabiedes, M. Rull-Gabayet, V. Pascual-Ramos Inadequate therapy behavior is associated to disease flares in patients with rheumatoid arthritis who have achieved remission with disease-modifying antirheumatic drugs Am J Med Sci, 340 (2010), pp. 282-290

[7] B.J.F. Van den Bemt Optimizing pharmacotherapy in patients with rheumatoid arthritis: an individualized approach The Netherlands, Radboud University Nijmegen (2009)

[8] F. Viller, F. Guillemin, S. Briancon, T. Moum, T. Suurmeijer, W. van den Heuvel Compliance to drug treatment of patients with rheumatoid arthritis: a 3 year longitudinal study J Rheumatol, 26 (1999), pp. 2114-2122

[9] R.B. Haynes, E. Ackloo, N. Sahota, H.P. McDonald, X. Yao Interventions for enhancing medication adherence Cochrane Database Syst Rev C, 4 (2008), p. CD000011

[10] H.L. Brus, M.A. van de Laar, E. Taal, J.J. Rasker, O. Wiegman Effects of patient education on compliance with basic treatment regimens and health in recent onset active rheumatoid arthritis Ann Rheum Dis, 57 (1998), pp. 146-151

[11] J. Hill, H. Bird, S. Johnson Effect of patient education on adherence to drug treatment for rheumatoid arthritis: a randomised controlled trial Ann Rheum Dis, 60 (2001), pp. 869875

[12] B.J.F. Van den Bemt, A.A. den Broeder, F.H. van den Hoogen, B. Benraad, Y.A. Hekster, P.L. van Riel et al. Making the rheumatologist aware of patients' non-adherence does not improve medication adherence in patients with rheumatoid arthritis Scand J Rheumatol, 40 (2011), pp. 192-196

[13] H. Zwikker, B. van den Bemt, C. van den Ende, W. van Lankveld, A. den Broeder, F. van den Hoogen et al. Development and content of a group-based intervention to improve medication adherence in non-adherent patients with rheumatoid arthritis Patient Educ Couns, 89 (2012), pp. 143-151

[14] Sabaté E. Adherence to long-term therapies: evidence for action [Internet] World Health Organization, Switzerland (2003) 209 pp. Available from http://whqlibdoc.who.int/publications/2003/9241545992.pdf [cited 01.11.13]

[15] S. Clifford, N. Barber, R. Elliott, E. Hartley, R. HornePatient-centred advice is effective in improving adherence to medicines Pharm World Sci, 28 (2006), pp. 165-170

[16] S. Clifford, N. Barber, R. Horne Understanding different beliefs held by adherers, unintentional nonadherers, and intentional nonadherers: application of the NecessityConcerns Framework J Psychosom Res, 64 (2008), pp. 41-46

[17] R.A. Elliott Poor adherence to medication in adults with rheumatoid arthritis: reasons and solutions Dis Manage Health Outcomes (2008), pp. 13-29

[18] R. Horne, J. Weinman Patients' beliefs about prescribed medicines and their role in adherence to treatment in chronic physical illness J Psychosom Res, 47 (1999), pp. 555567

[19] R. Horne, J. Weinman, M. Hankins The beliefs about Medicines Questionnaire: the development and evaluation of a new method for assessing the cognitive representation of medication Psychol Health (1999), pp. 1-24

[20] T.T. Menckeberg, M.L. Bouvy, M. Bracke, A.A. Kaptein, H.G. Leufkens, J.A. Raaijmakers et al.Beliefs about medicines predict refill adherence to inhaled corticosteroids 
Zwikker, H.E., Ende, C.H. van den, Lankveld, W.G. van, Broeder, A.A. den, Hoogen, F.H. van den, Mosselaar, B. van de, Dulmen, S. van, Bemt, B.J. van den. Effectiveness of a group-based intervention to change medication beliefs and improve medication adherence in patients with rheumatoid arthritis: a randomized controlled trial. Patient Education and Counseling: 2014, 94(3), 356-361

J Psychosom Res, 64 (2008), pp. 47-54

[21] R. Neame, A. Hammond Beliefs about medications: a questionnaire survey of people with rheumatoid arthritis Rheumatology (Oxford), 44 (2005), pp. 762-767

[22] B.J.F. Van den Bemt, F.H. van den Hoogen, B. Benraad, Y.A. Hekster, P.L. van Riel, W. van Lankveld Adherence rates and associations with nonadherence in patients with rheumatoid arthritis using disease modifying antirheumatic drugs J Rheumatol, 36 (2009),

pp. 2164-2170

[23] D. Moher, S. Hopewell, K.F. Schulz, V. Montori, P.C. Gotzsche, P.J. Devereaux et al. CONSORT 2010 explanation and elaboration: updated guidelines for reporting parallel group randomised trials Int J Surg, 10 (2012), pp. 28-55

[24] D. Aletaha, T. Neogi, A.J. Silman, J. Funovits, D.T. Felson, C.O. Bingham III et al. Rheumatoid arthritis classification criteria: an American College of Rheumatology/European League Against Rheumatism collaborative initiative Arthritis Rheum, 62 (2010), pp. 2569-2581

[25]E. De Klerk, D. van der Heijde, R. Landewe, H. van der Tempel, S. van der Linden The compliance-questionnaire-rheumatology compared with electronic medication event monitoring: a validation study J Rheumatol, 30 (2003), pp. 2469-2475

[26] L.K. Bartholomew, G.S. Parcel, G. Kok Intervention mapping: a process for developing theory- and evidence-based health education programs Health Educ Behav, 25 (1998), pp. 545-563

[27] E. Britt, S.M. Hudson, N.M. Blampied Motivational interviewing in health settings: a review Patient Educ Couns, 53 (2004), pp. 147-155

[28] M.J. Fryling, M.D. Wallace, J.N. Yassine Impact of treatment integrity on intervention effectiveness J Appl Behav Anal, 45 (2012), pp. 449-453

[29] C. Lane, M. Huws-Thomas, K. Hood, S. Rollnick, K. Edwards, M. Robling Measuring adaptations of motivational interviewing: the development and validation of the behavior change counseling index (BECCI) Patient Educ Couns, 56 (2005), pp. 166-173

[30] www.randomization.com (assessed 01.10.09).

[31] Horne R. The Medication Adherence Report Scale (MARS): a new measurement tool for eliciting patients' report non-adherence [Working paper]. Mayfield House, United Kingdom: University of Brighton (accessed 01.01.13).

[32] C.G. Grijalva, C.P. Chung, P.G. Arbogast, C.M. Stein, E.F. Mitchel Jr., M.R. Griffin Assessment of adherence to and persistence on disease-modifying antirheumatic drugs (DMARDs) in patients with rheumatoid arthritis Med Care, 45 (2007), pp. S66-S76

[33] J. Fransen, T. Langenegger, B.A. Michel, G. Stucki Feasibility and validity of the RADAI, a self-administered rheumatoid arthritis disease activity index Rheumatology (Oxford), 39 (2000), pp. 321-327

[34] B. Bruce, J.F. Fries The Stanford Health Assessment Questionnaire: dimensions and practical applications Health Qual Life Outcomes, 1 (2003), p. 20

[35] D.D. Price, F.M. Bush, S. Long, S.W. Harkins A comparison of pain measurement characteristics of mechanical visual analogue and simple numerical rating scales Pain, 56 (1994), pp. 217-226

[36] R. Horne, M. Hankins, R. Jenkins The Satisfaction with Information about Medicines Scale (SIMS): a new measurement tool for audit and research Qual Health Care, 10 (2001), pp. 135-140

[37] A.W. Evers, F.W. Kraaimaat, W. van Lankveld, P.J. Jongen, J.W. Jacobs, J.W. Bijlsma Beyond unfavorable thinking: the illness cognition questionnaire for chronic diseases J Consult Clin Psychol, 69 (2001), pp. 1026-1036 
Zwikker, H.E., Ende, C.H. van den, Lankveld, W.G. van, Broeder, A.A. den, Hoogen, F.H. van den, Mosselaar, B. van de, Dulmen, S. van, Bemt, B.J. van den. Effectiveness of a group-based intervention to change medication beliefs and improve medication adherence in patients with rheumatoid arthritis: a randomized controlled trial. Patient Education and Counseling: 2014, 94(3), 356-361

[38] R.P. Riemsma, E. Taal, J.J. Rasker Group education for patients with rheumatoid arthritis and their partners Arthritis Rheum, 49 (2003), pp. 556-566

[39] K. Lorig, R.L. Chastain, E. Ung, S. Shoor, H.R. Holman Development and evaluation of a scale to measure perceived self-efficacy in people with arthritis Arthritis Rheum, 32 (1989), pp. 37-44

[40] A.S. Zigmond, R.P. Snaith The hospital anxiety and depression scale Acta Psychiatr Scand, 67 (1983), pp. 361-370

[41] J.A. Butler, R.C. Peveler, P. Roderick, R. Horne, J.C. Mason Measuring compliance with drug regimens after renal transplantation: comparison of self-report and clinician rating with electronic monitoring Transplantation, 77 (2004), pp. 786-789

[42] J.F. Steiner, A.V. Prochazka The assessment of refill compliance using pharmacy records: methods, validity, and applications J Clin Epidemiol, 50 (1997), pp. 105-116

[43] StataCorp LP. Stata longitudinal-data/panel-data reference manual: release 11 Stata Press, College Station, TX, USA (2009)

[44] StataCorp LP Stata user's guide: release 11 College Station, TX, USA, Stata Press (2009)

[45] D.G. Altman Comparability of randomised groups The Statistician, 34 (1985), pp. 125136

[46] J.W.R. Twisk Applied longitudinal data analysis for epidemiology - a practical guide Cambridge University Press, Cambridge (2003)

[47] C.E. Hewitt, B. Kumaravel, J.C. Dumville, D.J. Torgerson Assessing the impact of attrition in randomized controlled trials

J Clin Epidemiol, 63 (2010), pp. 1264-1270

[48] B.G. Bender, A. Apter, D.K. Bogen, P. Dickinson, L. Fisher, F.S. Wamboldt et al.

Test of an interactive voice response intervention to improve adherence to controller medications in adults with asthma J Am Board Fam Med, 23 (2010), pp. 159-165

[49] J.W.R. Twisk, W. De Vente The analysis of randomised controlled trial data with more than one follow-up measurement. A comparison between different approaches Eur $\mathrm{J}$ Epidemiol, 23 (2008), pp. 655-660

[50] N. McNicholas, A. Patel, J. Chataway It is better to be in a clinical trial than not: lessons learnt from clinical neurology - the management of acute multiple sclerosis relapses QJM, 105 (2012), pp. 775-780

[51] J. Gamble, M. Stevenson, L.G. Heaney A study of a multi-level intervention to improve non-adherence in difficult to control asthma Respir Med, 105 (2011), pp. 1308-1315

[52] C. Willey, C. Redding, J. Staflord, F. Garfield, S. Geletko, T. Flanigan et al. Stages of change for adherence with medication regimens for chronic disease: development and validation of a measure Clin Ther, 22 (2013), pp. 858-871

[53] A. Pasma, A. van't Spijker, J.M. Hazes, J.J. Busschbach, J.J. Luime Factors associated with adherence to pharmaceutical treatment for rheumatoid arthritis patients: a systematic review Semin Arthritis Rheum, 43 (2013), pp. 18-28

[54] L.M. Hess, M.A. Raebel, D.A. Conner, D.C. Malone Measurement of adherence in pharmacy administrative databases: a proposal for standard definitions and preferred measures Ann Pharmacother, 40 (2006), pp. 1280-1288

[55] R. Pool, C.M. Montgomery, N.S. Morar, O. Mweemba, A. Ssali, M. Gafos et al. A mixed methods and triangulation model for increasing the accuracy of adherence and sexual behaviour data: the Microbicides Development Programme PLoS ONE, 5 (2010), p. e11600 
Zwikker, H.E., Ende, C.H. van den, Lankveld, W.G. van, Broeder, A.A. den, Hoogen, F.H. van den, Mosselaar, B. van de, Dulmen, S. van, Bemt, B.J. van den. Effectiveness of a group-based intervention to change medication beliefs and improve medication adherence in patients with rheumatoid arthritis: a randomized controlled trial. Patient Education and Counseling: 2014, 94(3), 356-361

[56] H. Zwikker, B. van den Bemt, J. Vriezekolk, C. van den Ende, S. Van Dulmen Psychosocial predictors of non-adherence to chronic medication: systematic review of longitudinal studies

\section{TABLES AND FIGURES}

Fig. 1. Participant flowchart.

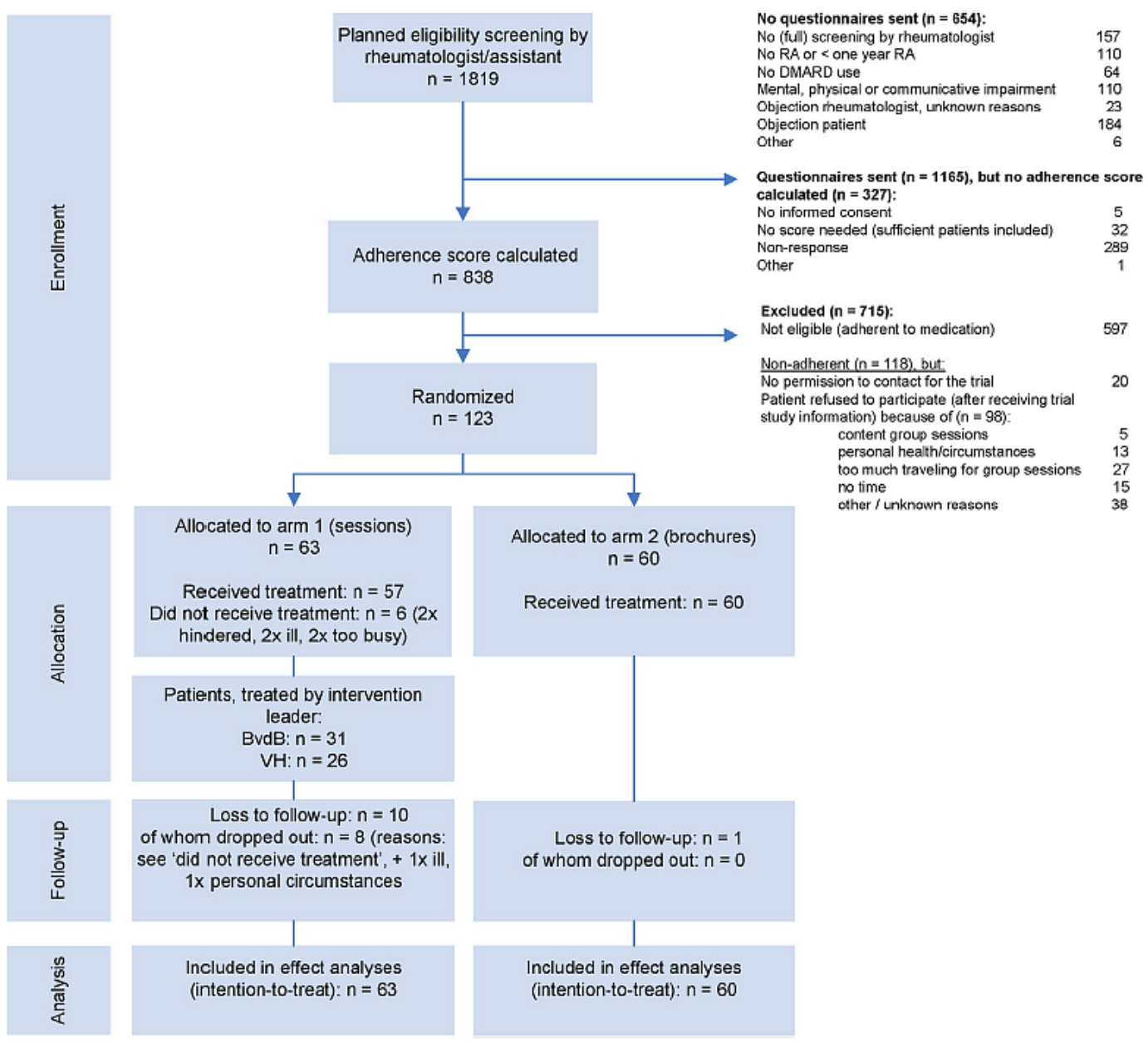


Zwikker, H.E., Ende, C.H. van den, Lankveld, W.G. van, Broeder, A.A. den, Hoogen, F.H. van den, Mosselaar, B. van de, Dulmen, S. van, Bemt, B.J. van den. Effectiveness of a group-based intervention to change medication beliefs and improve medication adherence in patients with rheumatoid arthritis: a randomized controlled trial. Patient Education and Counseling: 2014, 94(3), 356-361

Table 1

Baseline study sample characteristics. ${ }^{a}$

\begin{tabular}{|c|c|c|}
\hline Characteristics & $\begin{array}{l}\text { Arm } 1 \text { (sessions), } \\
n=63\end{array}$ & $\begin{array}{l}\text { Arm } 2 \text { (brochures), } \\
n=60\end{array}$ \\
\hline \multicolumn{3}{|l|}{ Socio-demographic characteristics } \\
\hline Age (years) & $60.4(12.1)$ & $59.3(11.3)$ \\
\hline Female & $42(66.7 \%)$ & $43(71.7 \%)$ \\
\hline Living with others & 44 (72.1\%) & $50(84.8 \%)$ \\
\hline Higher education ${ }^{\mathrm{b}}$ & 15 (24.6\%) & 15 (25.4\%) \\
\hline Currently employed/studying & $28(48.2 \%)$ & 31 (51.7\%) \\
\hline \multicolumn{3}{|l|}{ Clinical characteristics } \\
\hline $\begin{array}{l}\text { Disease duration (years) } \\
n \text { DMARDs used }{ }^{c, d}\end{array}$ & $15.3(10.5)$ & $14.2(9.1)$ \\
\hline 1 DMARD & 25 (41.7\%) & $36(61.0 \%)$ \\
\hline 2 DMARDs & $29(48.3 \%)$ & 17 (28.8\%) \\
\hline$\geq 3$ DMARDs & $6(10.0 \%)$ & $6(10.2 \%)$ \\
\hline \multicolumn{3}{|l|}{ Route of DMARD administration } \\
\hline Oral $^{c}$ & 43 (71.7\%) & $34(57.6 \%)$ \\
\hline Parenteral $^{\mathrm{d}}$ & $41(68.3 \%)$ & $38(64.4 \%)$ \\
\hline Rheumatoid factor (positive) & $29(78.4 \%)^{e}$ & $30(79.0 \%)^{\mathrm{e}}$ \\
\hline Anti-CCP (positive) & $24(72.7 \%)^{\mathrm{e}}$ & $24(68.6 \%)^{\mathrm{e}}$ \\
\hline RADAI disease activity $(0-10)^{\mathrm{f}}$ & $2.5(1.7)^{e}$ & $2.5(1.9)^{e}$ \\
\hline VAS pain score $(0-100 \mathrm{~mm})^{\mathrm{f}}$ & $27.2(19.2)$ & $26.8(21.0)$ \\
\hline HAQ Disability Index $(0-3)^{f}$ & $1.0(0.7)$ & $0.9(0.7)$ \\
\hline
\end{tabular}

${ }^{a}$ Data are means (SD) or numbers (\%).

b Higher education means having at least a bachelor's or master's degree.

c Azathioprine, hydroxychloroquine, leflunomide, methotrexate, prednisone/ prednisolone or sulfasalazine.

d Adalimumab, depomedrol, etanercept, methotrexate, abatacept, infliximab, or mabthera. Four patients received infusion mono-therapy.

e $>10 \%$ missing data. Number of non-missing cases in intervention and control arm is $37 / 38$ for the rheumatoid factor, $33 / 35$ for anti-CCP, and $51 / 52$ for the RADAI score, respectively.

${ }^{\mathrm{f}}$ Higher scores $=$ greater disability/disease activity/pain. 
Table 2

Adjusted effect sizes for beliefs about medication and medication non-adherence, 12 months afiter the intervention. ${ }^{\mathrm{a}}$

\begin{tabular}{|c|c|c|c|c|c|}
\hline \multirow[t]{2}{*}{ Measures } & \multicolumn{2}{|l|}{ T0: baseline, $n=119$} & \multicolumn{2}{|c|}{ T3: 12-month follow-up, $n=115$} & \multirow{2}{*}{$\begin{array}{l}\text { Adjusted effect size } \\
b(95 \% \mathrm{Cl})^{\mathrm{b}}\end{array}$} \\
\hline & Arm 1 (se:ssions) & Arm 2 (brochures) & Arrn 1 (sessions) & Arm 2 (brochures) & \\
\hline \multicolumn{6}{|l|}{ Beliefs about medication } \\
\hline BMQ specific necessity $(5-25)^{c}$ & $18.8(3.6)$ & $18.8(3.3)$ & $18.2(3.8)$ & $19.1(3.3)$ & $-1.0(-2.0,-0.1)^{e}$ \\
\hline BMQ specific concerns $(5-25)^{c}$ & $13.3(3.4)$ & $14.3(3.3)$ & $12.8(3.5)$ & $13.6(3.5)$ & $0.0(-1.0,1.1)$ \\
\hline BMQ differential $(-20 \text { to }+20)^{d}$ & $5.6(4.7)$ & $4.6(4.8)$ & $5.5(5.1)$ & $5.5(4.2)$ & $-1.1(-2.4,0.3)$ \\
\hline BMQ general overuse $(4-20)^{c}$ & $11.0(2.5)$ & $11.1(2.7)$ & $10.6(2.8)$ & $10.9(2.5)$ & $-0.2(-1.1,0.7)$ \\
\hline BMQ general harm $(4-20)^{c}$ & $9.9(2.5)$ & $10.0(2.6)$ & $9.8(2.5)$ & $10.1(2.3)$ & $-0.2(-0.9,0.5)$ \\
\hline \multirow[t]{2}{*}{ Measure:s } & \multicolumn{2}{|c|}{ T0: baseline, $n=119$} & \multicolumn{2}{|c|}{ T3: 12-month follow-up, $n=115$} & Adjusted effect size \\
\hline & Arm 1 (sessions) & Arm 2 (brochures) & Arm 1 (sessions) & Arm 2: (brochures) & OR $(95 \% \mathrm{CI})^{\mathrm{b}}$ \\
\hline \multicolumn{6}{|l|}{ Medication non-adherence } \\
\hline$C Q R$, nonl-adherent & $36(62.1 \%)$ & $40(67.8 \%)$ & $28(50.9 \%)$ & $29(49.2 \%)$ & $1.3(0.5,3.3)$ \\
\hline MARS, non-adherent & $32(54.2 \%)$ & 33 (56.9\%) & $30(54.6 \%)$ & $28(46.7 \%)$ & $1.7(0.8,3.8)$ \\
\hline \multirow[t]{2}{*}{ Measures } & \multicolumn{2}{|c|}{ TO: baseline, $n=119$} & \multicolumn{2}{|c|}{ T3: 12 -month follow-up, $n=115$} & Adjusted effect size \\
\hline & Arm 1 (sessions) & Arm 2 (brochures) & Arm 1 (sessions) & Arm 2: (brochures) & $\begin{array}{l}\text { Difference in means } \\
(95 \% \mathrm{Cl})^{f}\end{array}$ \\
\hline$\%$ Refill adherence & $94.4 \%$ & $103.1 \%$ & $96.6 \%$ & $102.0 \%$ & $2.2 \%(-11.1 \%, 15.6 \%)$ \\
\hline
\end{tabular}

- a Descriptive data are means (SD) or numbers (\%). Effect sizes (except for refill rate adherence) adjusted for age, sex, living with others yes/no, disease duration, parenteral medication yes/no, and baseline depression score (HADS).

b Regression coefficient or odds ratio(OR) with $95 \%$ confidence interval for the difference in outcome values between the intervention arm and control arm at 12 months' follow-up, corrected for baseline. Control arm =reference category. OR: odds of being non-adherent at 12 months' follow-up is smaller (OR<1) or bigger (OR $>1)$ for participants in the intervention arm in comparisorı with participants in the control arm.

${ }^{c}$ Higher scores indicate stronger beliefs.

d Positive scores mean that necessity beliefs about medication are stronger than concern beliefs about medication, and vice versa.

e $p$ value $\leq 0.05$.

The rnean change in refill adherence in participants in the intervention arm minus the mean change in refill adherence in participants in the control arm. 


\section{APPENDIX}

Appendix figure I - Trial randomization and implementation process

Weekly mailing of included patients to
the pharmacy secretary by researcher

Tasks of the secretary
$\begin{aligned} & \text { Every } \\
& \text { week }\end{aligned}$ \begin{tabular}{c}
$\begin{array}{c}\text { Assigning treatment to patients according } \\
\text { to randomization list (in combination with } \\
\text { order of patient inclusion) }\end{array}$ \\
\hline
\end{tabular}

Every
week

Dividing patients into clusters (based on order of inclusion and availability of patients)

\begin{tabular}{r|r}
$\begin{array}{r}4 \text { weeks } \\
\text { before start } \\
\text { interventions }\end{array}$ & $\begin{array}{l}\text { Mailing randomization outcome to } \\
\text { the individual patients in upcoming } \\
\text { cluster } \\
\text { Informing researcher about patient } \\
\text { composition of upcoming cluster } \\
\text { (note: researcher remains blind for } \\
\text { treatment allocation) }\end{array}$ \\
$\begin{array}{r}\text { refore start } \\
\text { interventions }\end{array}$ & \\
$\begin{array}{r}1 \text { week } \\
\text { before start } \\
\text { interventions }\end{array}$ & Mailing reminder to patients in upcoming \\
cluster about the intervention they will \\
receive
\end{tabular}

Sending baseline questionnaire (T0) to patients in upcoming round

Mailing reminder about baseline questionnaire to non-responding patients
Tasks of the secretary and intervention leader

Patients allocated to arm 1 receive brochure(s) AND attend group session 1

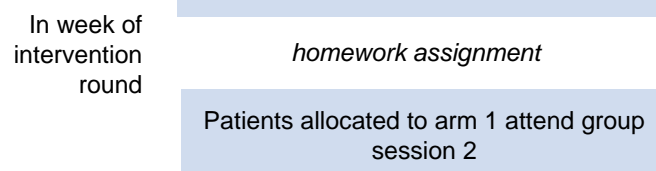

Patients allocated to arm 1 attend group session 2

\section{Tasks of the secretary}

Patients allocated to arm 2 receive brochure(s) at home

Tasks of the researcher

1 week after group session 2

Sending T1 questionnaire to patients in arm 1 and arm 2 (and a reminder, 2 weeks later)

$\underline{\text { Task of the intervention leader }}$

8 weeks after group session 2

Follow-up call to individual participants allocated to arm 1

\section{Tasks of the researcher}

6 months after group session 2

Sending T2 questionnaire to patients in arm 1 and arm 2 (and a reminder, 2 weeks later)

12 months after group session 2 
Appendix table SI - Treatment integrity: checklist and scores

\begin{tabular}{|c|c|c|c|c|c|}
\hline & Audio sessions of intervention leader $A$ or $B$ & & & & \\
\hline & A 11-1-2011 A 18-1-2011 B 15-3-2011 B 22-3-2011 & A 4-2-2011 & A 11-2-2011 & B 25-3-2011 & B 1-4-2011 \\
\hline FIRST GROUP SESSION (omission) & $1=$ addressed $/$ yes $0=$ not addressed $/$ no n.r. $=$ not reco & corded n.a. $=$ & $=$ not applicable $/$ & e/not brought 4 & up by patients \\
\hline \multicolumn{6}{|l|}{ Welcome } \\
\hline \multicolumn{6}{|l|}{ Explaining background of the group sessions } \\
\hline \multicolumn{6}{|l|}{ Exchanging experiences, thoughts, feelings, advantages, and disadvantages relating to the medication \& medication use } \\
\hline \multicolumn{6}{|l|}{ Provision of information about medicines by the intervention leader, whenever participants feel the need for this information } \\
\hline \multicolumn{6}{|l|}{ Intervenion leader emphasizes that he does not wish to dictate how medication should be used by the participants } \\
\hline \multicolumn{6}{|l|}{ Intervenion etiquette: intervention leader explains that: } \\
\hline \multicolumn{6}{|l|}{ experiences should be exchanged in an open, honest, and respectful way } \\
\hline \multicolumn{6}{|l|}{ participants should not try to convince each other } \\
\hline \multicolumn{6}{|l|}{ participants should actively contribute } \\
\hline \multicolumn{6}{|l|}{ Getting to know each other } \\
\hline \multicolumn{6}{|l|}{ Participants interview each other for about 15 minutes } \\
\hline \multicolumn{6}{|l|}{ Aim of the group sessions } \\
\hline \multicolumn{6}{|c|}{ To talk about the use of medication (including the fact that many patients skip medication doses, and the consequences of skipping doses } \\
\hline \multicolumn{6}{|l|}{ Discussing the necessity of using medication, concerns about medication, and practical barriers to taking medication } \\
\hline \multicolumn{6}{|l|}{ Introduction of the simple behavioral model } \\
\hline Explaining the meaning and role of a behavioral model in general & 1 & & 1 & 1 & t. \\
\hline
\end{tabular}




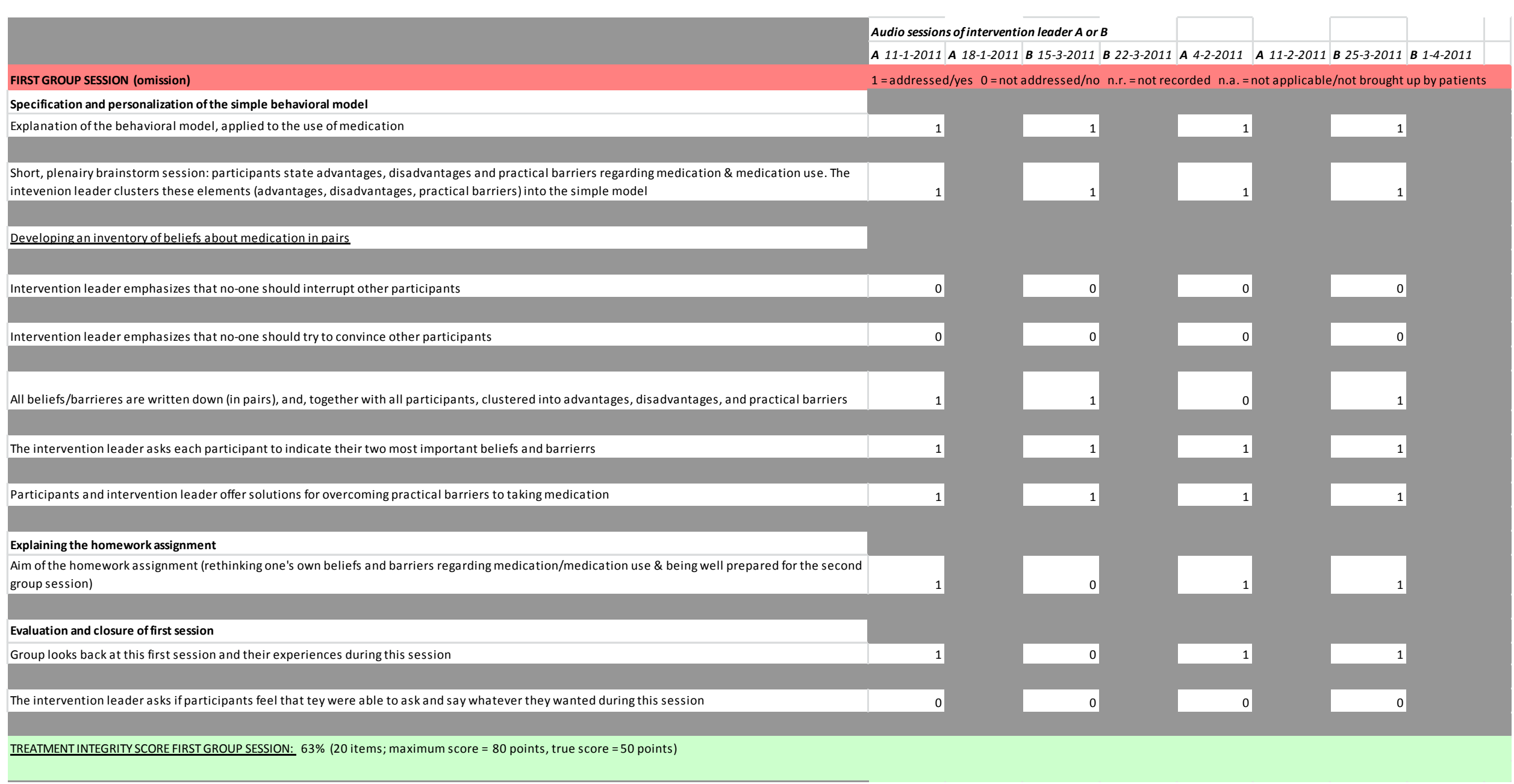




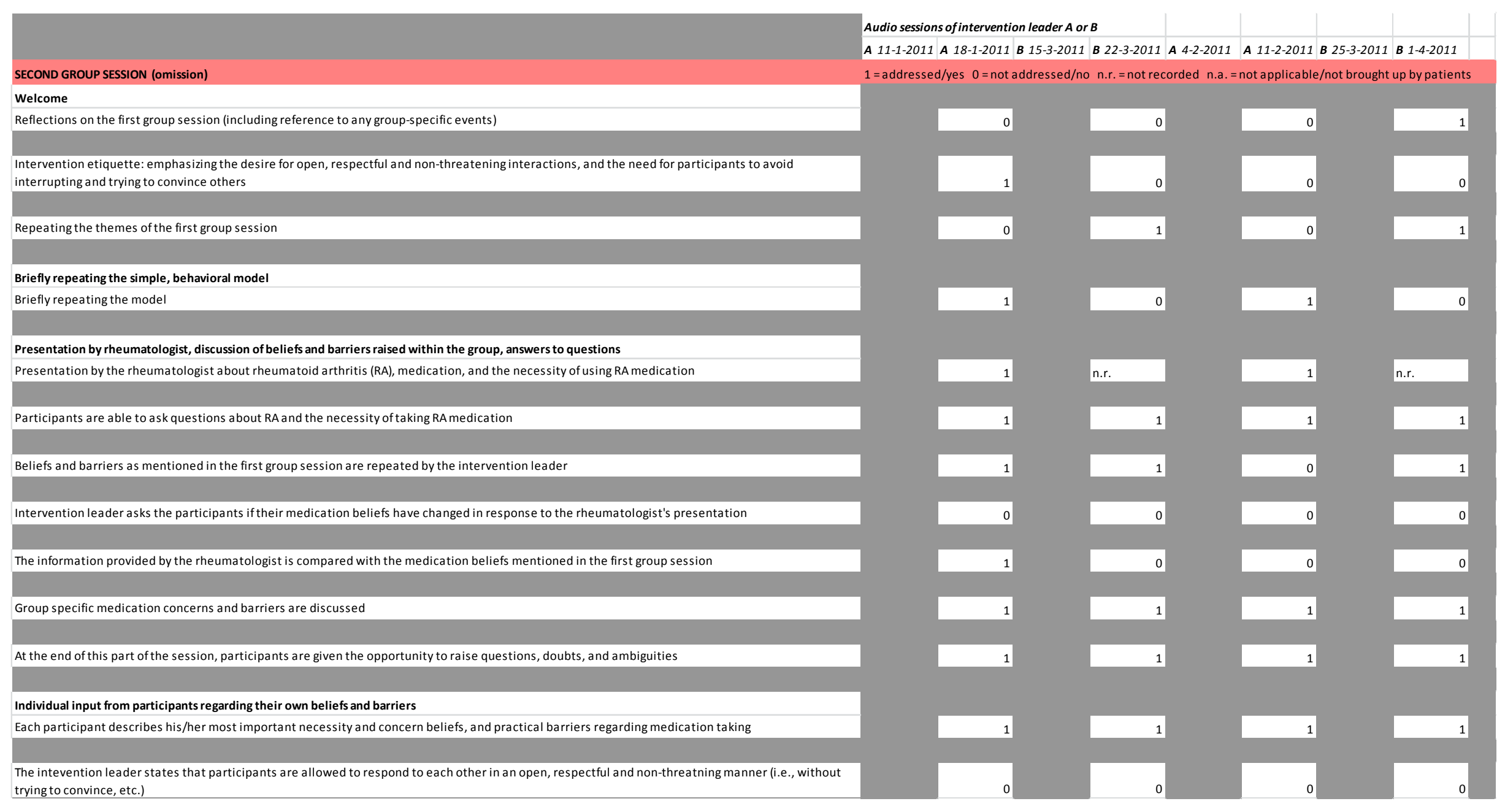


Appendix table SI - Treatment integrity: checklist and scores (continued)

\begin{tabular}{|c|c|c|c|c|c|c|c|c|}
\hline & Audio sessions & ns of interventic & ion leader $A$ or & & & & & \\
\hline & A 11-1-2011 & A 18-1-2011 & B 15-3-2011 & 1 B 22-3-2011 & A 4-2-2011 & 1 A 11-2-2011 & B 25-3-2011 & 1 B 1-4-2011 \\
\hline Degree of patient-centeredness (BECCI) & $0=$ not at all & $1=$ minimally & ly $2=$ to some & le extent $3=a g$ & good deal $4=$ & $4=a$ great extent & t n.a. $=$ not $a p$ & applicable \\
\hline Domain 1: agenda-setting and permission-seeking & & & & & & & & \\
\hline 1. The practitioner invites the patient to talk about behavior change & n.a. & n.a. & n.a. & n.a. & n.a. & n.a. & n.a. & n.a. \\
\hline 2. The practitioner demonstrates sensitivity to talking about other issues & 4 & 4 & & 4 & & 4 & 3 & 3 \\
\hline Domain 2: the why and how of change in behavior & & & & & & & & \\
\hline 3. Practitioner encourages patient to talk about current behavior or status quo & 3 & 2 & 1 & 1 & 2 & 3 & 2 & 2 \\
\hline 4. Practitioner encourages patient to talk about behavior change & n.a. & n.a. & n.a. & n.a. & n.a. & n.a. & n.a. & n.a. \\
\hline 5. Practitioner asks questions to elicit how patient thinks and feels about the topic & 4 & 4 & 4 & 4 & 4 & 4 & 3 & 3 \\
\hline 6. Practitioner uses empathic listening statements when patient talks about the topic & 4 & 4 & 4 & 4 & & 4 & 4 & 4 \\
\hline 7. Practitioner uses summaries to bring together what the patient says about the topic & 1 & 1 & 1 & 1 & & 1 & 1 & 1 \\
\hline Domain 3: the whole consultation & & & & & & & & \\
\hline 8. Practitioner acknowledges challenges about behavior change that the patient faces & 3 & 2 & 3 & 2 & & 3 & 3 & 3 \\
\hline 9. When practitioner provides information, it is sensitive to patient concerns and understanding & 4 & 4 & 4 & 4 & & 4 & 4 & 4 \\
\hline Domain 4: talk about targets & & & & & & & & \\
\hline 10. Practitioner actively conveys respect for patient choice about behaviour change & n.a. & n.a. & n.a. & n.a. & n.a. & n.a. & n.a. & n.a. \\
\hline 11. Practitioner and patient exchange ideas about how the patient could change current behavior & n.a. & n.a. & n.a. & n.a. & n.a. & n.a. & n.a. & n.a. \\
\hline${ }^{*}$ The intervention does not focus on changing behavior, but on changing beliefs about medic & & & & & & & & \\
\hline
\end{tabular}

